\title{
Aspergillus flavus Infection and Aflatoxin Contamination of Preharvest Maize in Benin
}

\author{
M. Sétamou, K. F. Cardwell, F. Schulthess, and K. Hell, Plant Health Management Division, International Insti- \\ tute of Tropical Agriculture (IITA), 08 BP 0932 Tri Postal, Cotonou, Republic of Benin
}

\begin{abstract}
Sétamou, M., Cardwell, K. F., Schulthess, F., and Hell, K. 1997. Aspergillus flavus infection and aflatoxin contamination of preharvest maize in Benin. Plant Dis. 81:1323-1327.

Eighty and sixty maize fields were sampled in 1994 and 1995, respectively, to monitor Aspergillus infection and aflatoxin contamination of preharvest maize in Benin. Three Aspergillus species were isolated from different agroecological zones, with $A$. flavus being the most prevalent. The countrywide mean percentage of kernel infection was about $20 \%$ in both years. Aflatoxin was extracted from maize in at least $30 \%$ of the fields sampled. Toxin concentrations exhibited a distinct zonal variation, with relatively high levels in the Guinea Savanna. There was a trend toward higher rate of aflatoxin accumulation per percentage A. flavus infection from the south to the north. Damage by the ear borer, Mussidia nigrivenella, increased aflatoxin accumulation in maize. Hence, the geographic pattern observed in the occurrence of $A$. flavus and aflatoxin may be related to the incidence of M. nigrivenella.
\end{abstract}

Although Aspergillus flavus Link:Fr. is described as a storage mold, it has been widely accepted that the infection of maize with this fungus occurs in the field. Preharvest infection of maize by A. flavus was noted as early as 1920 by Taubenhaus (16), and it has been shown to be abundant throughout kernel development. For many years, however, it was thought that preharvest maize was aflatoxin-free. It was only in 1973 that Lillehoj et al. (12) demonstrated the presence of aflatoxin B1 in maize before harvest. Since this survey was conducted, considerable work has been done to assess the importance of preharvest contamination of maize and to determine factors affecting the infection process by toxin-producing fungi, especially in the United States. Field infection is now well documented $(6,10)$. Although both $A$. parasiticus Speare and A. niger Tiegh. infect maize in the field, A. flavus appears to be the dominant aflatoxin-producing fungus (3), especially in tropical regions.

In tropical Africa, few studies have been carried out to determine the importance of A. flavus in preharvest maize. In Benin, maize constitutes a staple food of the population (4), and environmental conditions are suitable for the fungal growth. Preharvest infection of maize by A. flavus and subsequent aflatoxin production may

Corresponding author: K. F. Cardwell

E-mail: k.cardwell@cgnet.com

Accepted for publication 6 August 1997.

Publication no. D-1997-0915-01R

(C) 1997 The American Phytopathological Society constitute a serious problem. Hell et al. (5) reported that maize in Benin was heavily contaminated at an early stage of storage (1 to 2 months after harvest). This may have been due to high preharvest infection. This study was undertaken to elucidate this hypothesis. The objectives were to determine the distribution and the percentage of maize kernel infection by the fungus in Benin. Moreover, the relationship between A. flavus infection and the amount of aflatoxin produced in preharvest maize was established, and the involvement of insect damage to the ear in the process of aflatoxin contamination in preharvest maize was examined. Insects damaging maize grains have been shown to be significantly related to the incidence and level of aflatoxin contamination in preharvest maize $(1,11)$.

\section{MATERIALS AND METHODS}

Surveys. Two countrywide surveys were conducted in a 2-year study to evaluate the distribution of A. flavus and the most important factors determining aflatoxin levels in preharvest maize in Benin. The surveys were carried out in the 1994 and 1995 growing seasons in the four different agroecological zones: Coastal Savanna (CS), with two growing seasons (April to July and September to November) with average rainfall between 1,300 and $1,500 \mathrm{~mm}$ and maximum temperature from 25 to $35^{\circ} \mathrm{C}$; Southern Guinea Savanna (SGS), with the same seasonal pattern but with lower rainfall, averaging 1,200 to $1,300 \mathrm{~mm}$ and higher temperature maxima, ranging from 26 to $38^{\circ} \mathrm{C}$; Northern Guinea Savanna (NGS), characterized by one growing season (April to September), with average rainfall of 1,000 to $1,100 \mathrm{~mm}$ and tem- perature maxima from 28 to $40^{\circ} \mathrm{C}$; and Sudan Savanna (SS), with one growing season from late May to September but with low rainfall average ( 800 to $900 \mathrm{~mm}$ ) and high temperature maxima $\left(28\right.$ to $45^{\circ} \mathrm{C}$ ) (Fig. 1).

Twenty fields in 1994 and 15 in 1995 were sampled per zone. Fields ready for harvest, with plant materials completely dried, were visited in the second week of July for the two southern zones (CS and SGS) and in October for the two northern zones (NGS and SS). Within each field, 20 ears were randomly chosen. Maize samples were dissected immediately after harvest. The percentage of grains damaged and the number of insects feeding on ears were recorded per lepidopteran species, and for coleopteran species only the number of insects found was considered since their damage level at this period was less than $1 \%$ of total kernels. The lepidopteran species attacking ears, such as Mussidia nigrivenella and Cryptophlebia leucotreta, start their damage from the tip of the ear. C. leucotreta larvae penetrate the kernels and feed inside without noticeable frass, whereas $M$. nigrivenella larvae produce a lot of silky frass on the kernels, which is easily detected, as they bore into the kernels. The stem borers Sesamia calamistis and Eldana saccharina also feed on kernels, but their type of damage differs significantly from that of the ear borers. $S$. calamistis eggs are laid on the inner surface of the husks, and newly emerged larvae penetrate the ears and start feeding on the surface of the kernels. These larvae are often hidden by the frass they produce. $E$. saccharina larvae collected on ears generally emigrate from the stem to the ear. Hence, damage due to this borer goes from the rachis to the kernels, with abundant wet frass rejected on the surface of the kernels.

Fungal infection was first evaluated by estimating the percent area covered by visible hyphal growth of fungi on maize kernels. The ears were then put in paper bags and brought to the laboratory for evaluation of the fungal flora and aflatoxin determination.

Ears were oven-dried for 3 days at $45^{\circ} \mathrm{C}$ and then shelled separately. The kernels from each ear were mixed uniformly, and five kernels were selected arbitrarily for a total of 100 kernels per sample. The kernels were surface-disinfected for $1 \mathrm{~min}$ in $3.5 \% \mathrm{NaOCl}$, rinsed twice in sterile distilled water, and plated on sterile filter 
paper. Plated kernels were incubated at $25^{\circ} \mathrm{C}$ for 5 to 7 days. All cultures that developed from the kernels were identified directly on the plates, and percent kernel infection per fungal species was based on the total number of 100 kernels per field. The remaining kernels from ears selected per field were pooled, ground using a Romer Mill (Romer Labs Inc., Unio, MO) and assayed for aflatoxin by the method of Thomas et al. (17). A 50-g subsample was homogenized with $250 \mathrm{ml}$ of methanol and water $(60: 40 \mathrm{vol} / \mathrm{vol})$ with a mechanical shaker for $30 \mathrm{~min}$. The sedimented solution was then filtered, and the filtrate was first separated with a mixture of saturated sodium chloride and hexane solution. A second separation was done with chloroform, and the solution was drained into a conical flask containing $5 \mathrm{~g}$ of cupric carbonate. After shaking for about $30 \mathrm{~s}$, the cupric carbonate was allowed to settle, and the chloroform extract was filtered through Whatman filter paper no. 42 with a bed of anhydrous sodium sulfate into a beaker. This chloroform extract was left to evaporate. The residue was dissolved in $1 \mathrm{ml}$ of chloroform, transferred into a screw-cap vial, and kept in a refrigerator at $4{ }^{\circ} \mathrm{C}$ until qualitative and quantitative estimation.

Analysis of aflatoxins was performed by thin layer chromatography (TLC) (17), comparing it with a standard. The detection limit of the method was $1.6 \mathrm{ppb}$. Three spots of 5,10 , and $15 \mu \mathrm{l}$, respectively, of this chloroform extract were deposited on the base of precoated silica gel plates. Aflatoxin standard containing a mixture of aflatoxins B1, B2, and G1:G2 at 2.5, 0.75, and 2.5:0.75 ppb was also spotted at the rate of 5,10 , and $15 \mu \mathrm{l}$ on the same basis as the above spots. All spots were placed 1 $\mathrm{cm}$ from each other. The spotted plates were developed in a chloroform-acetone (96:4, vol/vol) solvent system for approximately $20 \mathrm{~min}$ so that the spots moved about $10 \mathrm{~cm}$. After that, they were dried using a commercial handheld hair drier. These plates were observed under long (365 nm) UV light fitted in a black cabinet. The intensity of fluorescence produced in spots of samples was compared with that of the standard. The volume of the matching spots of the sample and that of the standard were recorded. When the intensity of the fluorescence of the lowest concentration of the sample was too intense to match the standard, the sample extracts were diluted and re-chromatographed.

The concentration of aflatoxin in a maize sample $(\mu \mathrm{g} / \mathrm{kg}$ or $\mathrm{ppb})$ was calculated using the formula: $(S \times Y \times V) / W \times Z$, where $S=$ aflatoxin standard volume in $\mu$ l of equivalent intensity to $Z \mu \mathrm{l}$ of sample, $Y$ $=$ concentration of aflatoxin standard in $\mu \mathrm{g} / \mathrm{ml}, V=$ volume of solvent in $\mu \mathrm{l}$ required to dilute final extract, $W=$ weight of original sample in $g$ contained in final extract, and $Z=$ volume of sample extract in $\mu l$ required to give fluorescence intensity comparable to that of $S \mu \mathrm{l}$ of B1 standard.



Fig. 1. Incidence of Aspergillus flavus in maize at harvest (Benin, 1994 and 1995). 
Analysis of data. Total aflatoxins (B1, B2) as $x=p p b$ of sample were transformed to $\log (x+1)$, and all percentages were arcsine-transformed before analysis. The agroecological zones were coded according to decreasing rainfall from south to north, and the code used was: $1=\mathrm{CS}, 2=$ SGS, 3 $=$ NGS, and $4=$ SS. Analyses were performed with the SPSS for Windows program (14). Data were subjected to analysis of variance, and agroecological mean comparisons were done using the StudentNewman-Keuls test. Correlation and regression coefficients were calculated to establish relationships between variables. Data from each year were first analyzed separately, and then they were pooled.

\section{RESULTS}

The assessment of fungal contamination in preharvest maize in Benin revealed the presence of three species of Aspergillus ( $A$. flavus, A. niger, and A. parasiticus). A. flavus was the most frequent species, accounting for more than $98 \%$ of the Aspergilli isolated in both years. It was widely distributed in all four agroecological zones (Fig. 1). In 1994, A. flavus was detected in more than $80 \%$ of the fields, whereas in 1995 the fungus was found in $60 \%$ of the fields. Although the highest field incidence was always obtained in the SGS in both years, the trend of field infection by $A$. flavus observed in 1994 was different from that obtained in the 1995 growing season. High field incidence obtained in the NGS and SS fields in 1994 did not recur in the 1995 growing season. A. flavus was detected in only $33.3 \%$ of the fields of these zones in 1995, whereas in 1994, 85 and $75 \%$ of the fields were infected in the NGS and SS, respectively (Table 1). A. niger and $A$. parasiticus were less encountered than A. flavus. A. niger was detected from 20 and $14 \%$ of the samples in 1994 and 1995, respectively. The overall mean kernel infection was $1.44 \%$ in 1994 and $1.65 \%$ in 1995 . In both years, the SGS was the most infected by this fungus, but the infection level remained moderate (less than $4 \%$ of the kernels). A. parasiticus was found in only 6 and $8 \%$ of the samples in 1994 and 1995, respectively.

Only A. flavus hyphal growth was noticed on maize, but few kernels were affected in both years over the different agroecological zones. No significant differences were observed in the incidence of kernels showing visible $A$. flavus growth between the different agroecological zones $(F=1.87$ in 1994 and $F=2.02$ in 1995). The actual kernel infection by $A$. flavus obtained after the blotter test, however, revealed significant differences between the different agroecologies in both years (Table 1). In 1994, kernel infection ranged from $9.9 \%$ in the CS to $29.2 \%$ in the SGS, whereas in 1995 the percentage of kernels infected varied from $12.4 \%$ in the SS to $21.6 \%$ in the NGS. High percent kernel infection was always obtained in the Guinea Savanna zones (SGS and NGS). The CS had the lowest kernel infection in 1994, whereas in 1995 the lowest percentage of kernels invaded by A. flavus was recorded in the SS. Overall occurrence of the fungus on maize kernels was $20.6 \%$ in 1994 and 20\% in 1995.

Only B1 and B2 aflatoxins were detected from samples across the zones in both years. Overall, aflatoxin contamination revealed the same trend as Alavus infection (Table 1). The percentage of samples contaminated was higher in 1994 $(42.5 \%)$ than in 1995 (30\%). Aflatoxin contamination of samples varied widely according to agroecological zones in both years (Table 1). In 1994, the highest aflatoxin incidence was recorded in the NGS and SS, with $60 \%$ of the samples contaminated, whereas in 1995 the aflatoxin incidence was highest in the SGS (53.3\%). Comparing the percentage of samples contaminated by aflatoxin in the 2 years, a substantial increase was noticed in the two southern zones (CS and SGS), whereas a sharp decrease was evident in the two northern zones (NGS and SS).

Overall mean aflatoxin levels observed during the 2 years were comparable. Likewise, within each agroecological zone, mean aflatoxin levels did not vary greatly from 1994 to 1995. A similar trend was also observed in the distribution of mean aflatoxin levels of samples between agroecological zones. Samples from the SGS or the NGS accumulated more aflatoxin than the other zones. This shows a distinct, regional pattern of aflatoxin occurrence in Benin. The Guinea Savannas were more prone to aflatoxin accumulation in grains than the two other zones. In spite of high kernel infection by A. flavus in 1995, the CS environment was not conducive to high toxin production. In fact, with $80 \%$ of fields and $21.4 \%$ of kernels infected by $A$. flavus in the CS, aflatoxin was detected from only $33.3 \%$ of the samples, with a mean value of $23.3 \mathrm{ppb}$, whereas $53.3 \%$ of SGS samples were contaminated with levels as high as $262.9 \mathrm{ppb}$, with only $20.9 \%$ kernel infection.

Despite the low percentage of kernels showing visible fungal growth, a positive and significant correlation was obtained between percent kernels with visible $A$. flavus and percent kernels infected after the blotter test (Table 2). Likewise, percent kernels infected with $A$. flavus per sample was positively and significantly correlated with the corresponding aflatoxin levels of the samples. Hence, when the aflatoxin concentration of samples was regressed on the A. flavus kernel infection, a significant relationship was found to exist (Table 3 ). The slopes of regression indicating the amounts of aflatoxin produced per unit of kernel infection of samples were not significantly different between the 2 years $(t=$ 0.92). This shows that the aggressiveness of A. flavus did not vary from 1994 to 1995. Significant relationships were also obtained in each zone for the combined data of 1994 and 1995, between percent $A$.

Table 1. Percent fields with Aspergillus flavus infection and aflatoxin contamination of preharvest maize in the different agroecological zones of Benin (1994 and 1995)

\begin{tabular}{|c|c|c|c|c|c|c|c|c|}
\hline \multirow[b]{4}{*}{ Zone $^{w}$} & \multirow{2}{*}{\multicolumn{4}{|c|}{ A. flavus infection }} & \multicolumn{4}{|c|}{ Aflatoxin contamination } \\
\hline & & & & & \multirow{2}{*}{\multicolumn{2}{|c|}{ \% samples }} & \multirow{2}{*}{\multicolumn{2}{|c|}{$\begin{array}{c}\text { Mean aflatoxin } \mathbf{B 1}+\mathbf{B} 2 \\
\text { in contaminated samples }(\mathbf{p p b})^{\mathrm{y}}\end{array}$}} \\
\hline & \multicolumn{2}{|c|}{$\%$ fields } & \multicolumn{2}{|c|}{ Mean \% kernels ${ }^{x}$} & & & & \\
\hline & 1994 & 1995 & 1994 & 1995 & 1994 & 1995 & 1994 & 1995 \\
\hline Overall & 82.5 & 60 & 20.6 & 20.0 & 42.5 & 30 & $\begin{array}{l}136.8 \\
(5-2,500)^{\mathrm{z}}\end{array}$ & $\begin{array}{l}139.8 \\
(5-2,200)\end{array}$ \\
\hline $\mathrm{CS}$ & 70 & 80 & $9.9 \mathrm{a}$ & $21.4 \mathrm{~b}$ & 10 & 33.3 & $\begin{array}{l}16.7 \mathrm{a} \\
(16.7-16.7)\end{array}$ & $\begin{array}{l}23.3 \mathrm{a} \\
(16.7-50)\end{array}$ \\
\hline SGS & 95 & 93.3 & $29.2 \mathrm{~b}$ & $20.9 \mathrm{~b}$ & 40 & 53.3 & $\begin{array}{l}241.2 \mathrm{~b} \\
(5-2,500)\end{array}$ & $\begin{array}{r}262.9 \mathrm{~b} \\
(5-2,200)\end{array}$ \\
\hline NGS & 85 & 33.3 & $27.3 \mathrm{ab}$ & $21.6 \mathrm{~b}$ & 60 & 20 & $\begin{array}{l}109.5 \mathrm{~b} \\
(5-350)\end{array}$ & $\begin{array}{l}80.6 \mathrm{ab} \\
(16.7-165)\end{array}$ \\
\hline SS & 75 & 33.3 & $16.6 \mathrm{ab}$ & $12.4 \mathrm{a}$ & 60 & 13.3 & $\begin{array}{l}28.3 \mathrm{a} \\
(2-55)\end{array}$ & $\begin{array}{c}27.5 \mathrm{a} \\
(5-55)\end{array}$ \\
\hline
\end{tabular}

\footnotetext{
${ }^{\mathrm{w}}$ CS = Coastal Savanna, SGS = Southern Guinea Savanna, NGS = Northern Guinea Savanna, SS = Sudan Savanna.

${ }^{x}$ Means followed by the same letter in each column are not significantly different $(P<0.05)$ using Student-Newman-Keuls test.

y All percentages and concentrations were back-transformed after analysis.

${ }^{\mathrm{z}}$ Values in parenthesis represent aflatoxin range observed in positive samples.
} 
flavus kernel infection and aflatoxin levels (Table 3). There was a trend of increase in aflatoxin produced per unit of percent $A$. flavus kernel infection from the south to the north. The amount of aflatoxin produced per unit of A. flavus infection obtained in the CS was far lower than that of the three other zones. In 1994, a positive and significant correlation was observed between aflatoxin levels and agroecological zone (Table 2). This relationship was not significant in the 1995 growing season.

Four lepidopteran species, Mussidia nigrivenella Ragonot (Lepidoptera: Pyralidae), Cryptophlebia leucotreta Merick (Lep.: Tortricidae), Sesamia calamistis Hampson (Lep.: Noctuidae), and Eldana saccharina Walker (Lep.: Pyralidae), and four coleopteran species, i.e., Sitophilus zeamais (Motsch.) (Coleoptera: Cucurlionidae), Tribolium castaneum (Herbst), Carpophilus sp. (Col.: Nitidulidae), and Cathartus quadricolis (Guerin-Meneville) (Col.: Silvanidae), were found damaging preharvest maize. Of these insect pests collected feeding on maize ears, only the damage level of $M$. nigrivenella was found to be significantly correlated to A. flavus infection and aflatoxin contamination. Table 2 showed that the toxin levels were strongly related to the damage of this ear borer.

\section{DISCUSSION}

The occurrence of fungal flora in maize samples found in this 2-year study showed that preharvest infection of maize with $A$. flavus in Benin is common. These findings confirmed the hypothesis that heavy $A$. flavus infection and aflatoxin levels observed in maize in 1994 early in storage may be due to considerable preharvest infection (5). In 1993, Bouraima et al. (2) found that maize sold in Benin markets was sometimes contaminated with high levels of aflatoxins. Aflatoxin content of foods and feeds is regulated in many developed countries; and in some products including maize, aflatoxin levels below 20 $\mathrm{ng} / \mathrm{g}$ are mandated (15). The combined data of the 2 years clearly showed that more than $35 \%$ of the maize in Benin presents a risk for human consumption at harvest and thus reduce the competitiveness of maize from Benin on the international market. The differences in percent kernel infected by A. flavus between the different agroecological zones may be due to prevailing climatic conditions in the different zones, the cultivars grown in each zone, the cultural practices, and the incidence of $M$. nigrivenella. There was a clear tendency to higher aflatoxin accumulation in the SGS and NGS. Jones et al. (8) showed that high temperatures favored the infection of A. flavus and the development of aflatoxin in maize prior to harvest. In Benin, the temperature increases from the CS toward the SS; which would lead to more aflatoxin accumulation in the SS. Thus, fungal infection and aflatoxin accumulation are complex phenomena that are mediated by more than temperature alone. In 1992, Barry et al. (1) stated that aflatoxin production and contamination in preharvest maize includes many complex relationships among insects, fungi, maize genotypes, and the environment. The increase in aflatoxin concentration observed from the south to the north regions suggests that environmental characteristics of the different agroecologies may affect toxin contamination. No attempt was made to study the cultivars grown in each zone, but heterogeneity in maize genotype within and between agroecologies was encountered during the surveys, and it is well established that field aflatoxin accumulation varies with maize genotype or cultivar (9). Different cultural practices are shown to have an impact on aflatoxin development (7). Nitrogen supply has been shown to decrease aflatoxin contamination (7). Because the fields in the NGS and SS are frequently supplied with chemical fertilizers, plants should have shown less aflatoxin contamination. However, the current data did not reveal such a trend.

The involvement of insect pests in aflatoxin contamination is well established for the European corn borer (Ostrinia nubilalis Hübner), the corn earworm (Heliothis zea Boddie) (11), and the nitidulid beetle (Carpophilus lububris Murr.) (13). Since $M$. nigrivenella damage varied significantly between zones (from $2.7 \%$ of kernels in the SS to $7.1 \%$ in the NGS) and was found to be closely associated with aflatoxin levels found in samples, it is possible that this borer plays a determinant role in the eventual accumulation of toxin in maize in the zones where it occurs.

Although the study examined samples from only 80 and 60 fields in 1994 and 1995 , respectively, the results clearly indicate that aflatoxin contamination is occurring in preharvest maize in Benin. Therefore, more detailed studies are needed to determine the key factors of A. flavus infection and aflatoxin accumulation before management programs can be undertaken for minimizing maize qualitative losses due to the fungal activity.

\section{ACKNOWLEDGMENTS}

We thank the Deutsche Gesellschaft für Technische Zusammenarbeit (GTZ), Federal Republic of Germany, for supporting this project, S. Nokoe and $\mathrm{O}$. Bonato for statistical advice, and the staff of the Aspergillus project laboratory of IITA for technical assistance.

Table 3. Simple regression analysis of total aflatoxin in preharvest maize on percent kernel infection per field in 1994 and 1995 growing seasons, Benin

\begin{tabular}{lcccrc}
\hline & Intercept & Slope & $\boldsymbol{R}^{\mathbf{2}}$ & $\boldsymbol{t}$ & $\boldsymbol{P}$ \\
\hline 1994 growing season & -0.087 & 0.031 & 0.48 & 8.44 & $<0.005$ \\
1995 growing season & -0.106 & 0.037 & 0.68 & 11.10 & $<0.0001$ \\
Combined data (1994 and 1995) & & & & \\
CS & -0.230 & 0.017 & 0.52 & 5.68 & $<0.0001$ \\
SGS & -0.180 & 0.039 & 0.60 & 6.58 & $<0.0001$ \\
NGS & -0.003 & 0.042 & 0.77 & 10.13 & $<0.0001$ \\
SS & -0.052 & 0.046 & 0.71 & 7.97 & $<0.0001$ \\
\hline
\end{tabular}

${ }^{\mathrm{z}}$ CS $=$ Coastal Savanna, SGS = Southern Guinea Savanna, NGS = Northern Guinea Savanna, SS = Sudan Savanna.

Table 2. Correlation coefficients $(r)$ among Aspergillus flavus infection, aflatoxin concentration, ecological zone, and Mussidia nigrivenella damage to preharvest maize in Benin for 1994 and 1995 growing seasons

\begin{tabular}{|c|c|c|c|c|c|c|c|c|c|c|}
\hline \multirow[b]{2}{*}{ Year } & \multicolumn{2}{|c|}{$\begin{array}{c}\text { Kernels with visible } \\
\text { A. flavus }(\%) \\
\end{array}$} & \multicolumn{2}{|c|}{$\begin{array}{c}\text { Kernels infected with } \\
\text { A. flavus }(\%)\end{array}$} & \multicolumn{2}{|c|}{$\begin{array}{l}\text { Kernels damaged by } \\
\text { M. nigrivenella }(\%)\end{array}$} & \multicolumn{2}{|c|}{$\begin{array}{c}\text { Total aflatoxin in } \\
\text { maize samples (ng/g) }\end{array}$} & \multicolumn{2}{|c|}{ Agroecological zone } \\
\hline & 1994 & 1995 & 1994 & 1995 & 1994 & 1995 & 1994 & 1995 & 1994 & 1995 \\
\hline $\begin{array}{l}\text { Kernels with visible } \\
\text { A. flavus }(\%)\end{array}$ & 1.00 & 1.00 & & & & & & & & \\
\hline $\begin{array}{l}\text { Kernels infected with } \\
\text { A. flavus }(\%)\end{array}$ & $0.38 * * \mathrm{z}$ & $0.38 * *$ & 1.00 & 1.00 & & & & & & \\
\hline $\begin{array}{l}\text { Kernels damaged by } \\
\text { M. nigrivenella }(\%)\end{array}$ & 0.12 & -0.02 & $0.35 * *$ & $0.42 * *$ & 1.00 & 1.00 & & & & \\
\hline $\begin{array}{l}\text { Total aflatoxin in } \\
\text { maize samples (ng/g) }\end{array}$ & 0.21 & 0.21 & $0.69 * *$ & $0.82 * *$ & $0.36 * *$ & $0.52 * *$ & 1.00 & 1.00 & & \\
\hline Agroecological zone & 0.06 & -0.06 & 0.02 & $-0.42 * *$ & 0.02 & $-0.32 *$ & $0.23 *$ & -0.10 & 1.00 & 1.00 \\
\hline
\end{tabular}

$\mathrm{z} *$ and $* *$ denote significance from zero at the 5 and $1 \%$ levels, respectively. 


\section{LITERATURE CITED}

1. Barry, D., Widstrom, N. W., Darrah, L. L., McMillan, W. W., Riley, T. J., Scott, G. E., and Lillehoj, E. B. 1992. Maize ear damage by insects in relation to genotype and aflatoxin contamination in preharvest maize grain. J. Econ. Entomol. 85:2492-2495.

2. Bouraima, Y., Ayi-Fanou, L., Kora, I., Setondji, J., Sanni, A., and Creppy, E. E. 1993. Mise en évidence de la contamination des céréales par les aflatoxines et l'ochratoxine au Bénin. Hum. Ochratoxicosis Pathol. 231:101-110.

3. Calvert, O. H., Lillehoj, E. B., Kwolek, W. F., and Zuber, M. S. 1978. Aflatoxin $B_{1}$ and $G_{1}$ production in developing Zea mays kernels from mixed inocula of Aspergillus flavus and A. parasiticus. Phytopathology 68:501-506.

4. CIMMYT. 1990. Le potentiel maïsicole de l'Afrique Subsaharienne. CIMMYT, El Batan, Mexico.

5. Hell, K., Cardwell, K. F., Schultz, F. A., and Sétamou, M. 1995. Aflatoxin B1 contamination of traditional stores in four agroecological zones of Benin. 1356:1356 in: XIII International Plant Protection Congress. The Hague, The Netherlands. Eur. J. Plant Pathol.

6. Hesseltine, C. W., Shotwell, O. L., Kwolek,
W. F., Lillehoj, E. B., Jackson, W. K., and Bothast, R. J. 1976. Aflatoxin occurrence in 1973 corn at harvest. II. Mycological studies. Mycologia 68:341-353.

7. Jones, R. K., and Duncan, H. E. 1981. Effect of nitrogen fertilizer, planting date, and harvest date on aflatoxin production in corn inoculated with Aspergillus flavus. Plant Dis. 65:741-744.

8. Jones, R. K., Duncan, H. E., Payne, G. A., and Leonard, K. J. 1980. Factors influencing infection by Aspergillus flavus in silk-inoculated corn. Plant Dis. 64:859-863.

9. Kang, M. S., Lillehoj, E. B., and Widstrom, N. W. 1990. Field aflatoxin contamination of maize genotypes of broad genetic base. Euphytica 51:19-32.

10. Lillehoj, E. B., Fennell, D. I., and Kwolek, W. F. 1977. Aflatoxin and Aspergillus flavus occurrence in 1975 corn harvest from a limited region of Iowa. Cereal Chem. 54:366-372.

11. Lillehoj, E. B., Fennell, D. I., Kwolek, W. F., Adams, G. L., Zuber, M. S., Horner, E. S., Widstrom, N., Warren, H., Guthrie, W. D., Sauer, D. B., Findley, W. R., Manwiller, A., Josephson, L. M., and Bockholt, A. J. 1978. Aflatoxin contamination of corn before har- vest: Aspergillus flavus association with insects from developing ears. Crop Sci. 18:921 924.

12. Lillehoj, E. B., Kwolek, W. F., Fennell, D. I. and Milburn, M. S. 1975. Aflatoxin incidence and association with bright greenish-yellow fluorescence and insect damage in a limited survey of freshly harvested high-moisture corn. Cereal Chem. 52:403-412.

13. Lussenhop, J., and Wicklow, D. T. 1990 Nitidulid beetles (Nitidulidae: Coleoptera) as vectors of Aspergillus flavus in preharvest maize. Trans. Mycol. Soc. Jpn. 31:63-74.

14. Norusis, M. J., and SPSS Inc. 1993. SPSS for Windows: Advanced Statistics, Release 6.0 SPSS Inc., Chicago.

15. Stoloff, L., van Egmond, H. P., and Park, D. L. 1991. Rationales for the establishement of limits and regulations for mycotoxins. Food Addit. Contam. 8:213-222.

16. Taubenhaus, J. J. 1920. A study of the black and the yellow molds of ear corn. Tex. Agric. Exp. Stn. Bull. 270.

17. Thomas, F., Eppley, R. M., and Trucksess, M. W. 1975. Rapid screening method for aflatoxins and zearalenone in corn. J. Assoc. Off. Anal. Chem. 58:114-116. 